\title{
Vasculogenic and angiogenic potential of adipose stromal vascular fraction cell populations in vitro
}

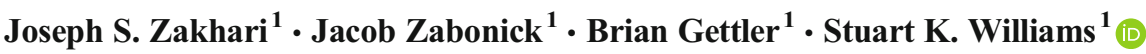

Received: 23 August 2017 / Accepted: 17 October 2017 / Published online: 1 December 2017 / Editor: Tetsuji Okamoto

(C) The Author(s) 2017. This article is an open access publication

\begin{abstract}
Adipose-derived stromal vascular fraction (SVF) is a heterogeneous cell source that contains endothelial cells, pericytes, smooth muscle cells, stem cells, and other accessory immune and stromal cells. The SVF cell population has been shown to support vasculogenesis in vitro as well vascular maturation in vivo. Matrigel, an extracellular matrix (ECM) mixture has been utilized in vitro to evaluate tube formation of purified endothelial cell systems. We have developed an in vitro system that utilizes freshly isolated SVF and ECM molecules both in pure form (fibrin, laminin, collagen) as well as premixed form (Matrigel) to evaluate endothelial tip cell formation, endothelial stalk elongation, and early stages of branching and inosculation. Freshly isolated SVF rat demonstrate cell aggregation and clustering (presumptive vasculogenesis) on Matrigel ECM within the first $36 \mathrm{~h}$ of seeding followed by tip cell formation, stalk cell formation, branching, and inosculation (presumptive angiogenesis) during the subsequent 4 days of culture. Purified ECM molecules (laminin, fibrin, and collagen) promote cell proliferation but
\end{abstract}

Electronic supplementary material The online version of this article (https://doi.org/10.1007/s11626-017-0213-7) contains supplementary material, which is available to authorized users.

Stuart K. Williams

cvregen@gmail.com

Joseph S. Zakhari

jszakh01@ louisville.edu

Jacob Zabonick

jakezabonick@gmail.com

Brian Gettler

brian.gettler@louisville.edu

1 Bioficial Organs Program, Cardiovascular Innovation Institute, 302 E. Muhammad Ali Blvd, Louisville, KY 40202, USA do not recapitulate events seen on Matrigel. We have created an in vitro system that provides a functional assay to study the mechanisms of vasculogenesis and angiogenesis in freshly isolated SVF to characterize SVF's blood vessel forming potential prior to clinical implantation.

Keywords Angiogenesis · Vasculogenesis · Adipose · Stromal vascular fraction

\section{Introduction}

Tissue engineering, the microvasculature is a novel approach towards therapeutic reperfusion for ischemic disease states such as peripheral vascular disease and acute myocardial infarction (Laschke and Menger 2015; Laschke and Menger 2016; Riemenschneider et al. 2016; Sun et al. 2016; Bogorad et al. 2017; Kc et al. 2017; Valarmathi et al. 2017). Microvascular engineering requires both cellular and extracellular components to recapitulate the microenvironment and tissue organization of endogenous microcirculation. Indeed, many researchers have isolated vascular components from a variety of tissues including endothelial-only populations from both large vessel (human umbilical vein and other large adult vessels) and microvascular tissues (Haug et al. 2015; Sasagawa et al. 2016; Morrissette-McAlmon et al. 2017). In vitro studies have established the ability of these endothelial cells to undergo the formation of tube-like structures, a process that is highly dependent on the extracellular matrix used as a substrate (Madri and Williams 1983).

Additionally, adipose-derived stromal vascular fraction (SVF) cells have been proposed as a source of cells for microvascular tissue engineering (Leblanc et al. 2013; Nunes et al. 2013; Maijub et al. 2015; Jin et al. 2017). Adipose-derived SVF represents a heterogeneous cell population (Wagner et al. 
1972; Wagner and Matthews 1975) that has demonstrated efficacy in the formation of functional microcirculation following implantation (Shepherd et al. 2007; Hiscox et al. 2008; Chang et al. 2012; Leblanc et al. 2012). These in vivo studies are based, in part, on the observed ability of SVFderived, cultured, microvascular endothelial cells to undergo tube formation in vitro (Madri and Williams 1983); however, and the impetus for the studies reported here, the in vitro formation of tube-like structures by freshly isolated, heterogeneous SVF cell populations has not been reported.

Previous in vitro "angiogenesis" assays have utilized endothelial cell cultures placed on collagen type IV or Matrigeltreated culture surfaces with a temporal sequence of tube-like structure formation that occurs within $24 \mathrm{~h}$ of plating (Madri and Williams 1983; Nicosia and Ottinetti 1990; Albini 2016; Brown et al. 2016). It can be argued that this self-assembly of cells into tube-like structures does not recapitulate the process known as angiogenesis (i.e., formation of new vessels from pre-existing vessel) and recapitulates only one part of the vasculogenic process (i.e., formation of blood vessels from cellular components). The current studies are based on preliminary observations that freshly isolated adipose-derived SVF cell populations that do not undergo tube-like structure formation in the first $24 \mathrm{~h}$ after plating on Matrigel. However, extending the assessment of the adipose SVF cell populations plated on Matrigel for a 7-d period resulted in the observation of cell aggregation, tip cell formation, sprouting of vascular structures followed by branching, and inosculation. Herein, we describe an in vitro assay that we propose which captures each step of vasculogenesis and angiogenesis over a 7-d period via time-lapse microscopy utilizing rat epididymal fat or human lipoaspirate-derived SVF as a cell source.

\section{Materials and Methods}

SVF isolation from Sprague Dawley rats Rat epididymal fat pads were excised from 6- to 8-month-old Sprague Dawley rats at weights greater than $250 \mathrm{~g}$ under sterile surgical procedure and isoflurane anesthesia. All procedures were reviewed and approved under the University of Louisville's Institutional Animal Care and Use Committee. Excised fat pads were placed in PBS containing $0.1 \%$ bovine serum albumin (Sigma-Aldrich, St. Louis, MO) and kept at $4^{\circ} \mathrm{C}$ for $15 \mathrm{~min}$ prior to digestion. Samples were washed with BSA-PBS and minced for 2 min until particulates could pass through a $50-\mathrm{mL}$ aspirating pipette. Two milligrams of type I collagenase (Worthington Biochemical Corporation, Lakewood, NJ) was added per milliliter of fat, aliquoted at $20 \mathrm{~mL}$ total volume in $50 \mathrm{~mL}$ conicle centrifuge tubes and rotated in an EnviroGenie incubator (Scientific Industries, Bohemia, NY) at $35 \mathrm{rpm}$ and $37^{\circ} \mathrm{C}$ for $35 \mathrm{~min}$. Samples were pelleted via centrifugation at $350 \times \mathrm{g}$ for $4 \mathrm{~min}$ at room temperature (RT).
Buoyant adipocytes were aspirated and discarded, and dense cellular pellets were suspended and washed one time in BSAPBS. Samples were recentrifuged for $4 \mathrm{~min}$ at $350 \times \mathrm{g}$. The SVF pellet was filtered through a $250-\mu \mathrm{m}$ mesh filter (Tissue Genesis Incorporated, Honolulu, HI) and collected into DMEM containing endothelial cell growth supplement, $2 \mathrm{mM}$ L-glutamine, $10 \%$ fetal bovine serum, and $5 \mathrm{mM}$ Hepes buffer. Samples were kept at RT prior to plating.

SVF isolation from human lipoaspirate Human lipoaspirate was digested under sterile conditions following the same protocol as rat SVF isolation. Briefly, lipoaspirate was provided from de-identified patients undergoing general nonultrasound-guided lipoaspiration. Lipoaspirate was washed with $0.1 \%$ BSA-PBS to provide non-bloody yellow fat. Subsequently, Worthington collagenase type I enzyme was added to obtain a final concentration of $6 \mathrm{mg} / \mathrm{mL}$ collagenase to fat volume. Samples were digested in an Enviro-Genie at $35 \mathrm{rpm}$ and $37^{\circ} \mathrm{C}$ for $35 \mathrm{~min}$. Samples were pelleted via centrifugation at $350 \times g$ for $4 \mathrm{~min}$ at RT. Buoyant adipocytes were aspirated and discarded, and dense cellular pellets were suspended and washed one time in BSA-PBS. Samples were recentrifuged for $4 \mathrm{~min}$ at $350 \times g$. The SVF pellet was filtered through a $250-\mu \mathrm{m}$ mesh filter. The SVF pellet was resuspended in M199 media containing endothelial cell growth supplement, $10 \%$ fetal bovine serum, $2 \mathrm{mM} \mathrm{L}$-glutamine, and $5 \mathrm{mM}$ Hepes buffer.

Angiogenesis assay and image capture Either $500 \mu \mathrm{L}$ of growth factor-reduced Matrigel (Corning, Corning, NY), $5 \mathrm{mg} / \mathrm{mL}$ bovine fibrin (Sigma, St. Louis, MO), $3 \mathrm{mg} / \mathrm{mL}$ rat tail collagen (Corning, Corning, NY), $1 \%$ porcine gelatin (Sigma, St. Louis, MO), or $2 \mu \mathrm{g}$ Laminin 332 (Abcam, Cambridge, MA) was added to each well of a 48-well polystyrene cell culture plate (Corning, Corning, NY) at $4^{\circ} \mathrm{C}$. Fibrin was polymerized through thrombin activation at $2 \mathrm{U} /$ $\mathrm{mg}$ fibrinogen. Collagen was polymerized after the addition of $4 \mathrm{~N} \mathrm{NaOH}$ to a $\mathrm{pH}$ of 7.7 and incubation at $37^{\circ} \mathrm{C}$. The Matrigel, fibrin, and collagen hydrogels solidified after $15 \mathrm{~min}$ of incubation at $37^{\circ} \mathrm{C} .1 .6 \times 10^{5} \mathrm{SVF}$ cells were subsequently plated per well and allowed to adhere to the ECM overnight in a tissue culture incubator $\left(37^{\circ} \mathrm{C}, 5 \% \mathrm{CO}_{2}\right)$. Media was changed the following $\mathrm{d}$, and the 48 -well plates were loaded into a Cytation 5 cell imaging multi-mode reader (Biotek, Winooski, VT) set to $37^{\circ} \mathrm{C}$ and $5 \% \mathrm{CO}_{2}$. A timelapse capture experiment was created in Gen5 software utilizing a $\times 4$ objective capturing phase contrast images at $15 \mathrm{~min}$ intervals with an endpoint of $160 \mathrm{~h}$. The media was changed every other day. Specific inhibitors of angiogenesis were added at 25 or $1 \mu \mathrm{M}$ at each media change over the 160 -h incubation time. Inhibitors included imatinib mesylate $(1 \mu \mathrm{M})$ (Sigma-Aldrich, St. Louis, MO); DAPT $(25 \mu \mathrm{M})$ (Abcam, Cambridge, UK); ZM $306416(25 \mu \mathrm{M})$ (Selleckchem, 
Houston, TX); and ATN $161(25 \mu \mathrm{M})$ (Peptides International, Louisville, KY).

Image files were stitched together using ImageJ software. Individual still images were selected at remarkable time points to demonstrate events such as clustering $(18 \mathrm{~h})$, tip cell formation (36 h), stalk cell formation $(60 \mathrm{~h})$, and inosculation $(112 \mathrm{~h})$. SVF and huvec cells grown on Matrigel to the 112$\mathrm{h}$ endpoint were fixed with $4 \%$ paraformaldehyde for $15 \mathrm{~min}$ at RT, permeabilized with $0.1 \%$ Triton X 100 for 15 min at RT, and stained with Griffonia simplicifolia 1 lectin conjugated to FITC (1:500) (Vector Biotechnologies, Burlingame, CA) and $\alpha$-smooth muscle actin mouse monoclonal primary antibody (1:500) (Santa Cruz Biotechnology, Dallas, TX) overnight at $4^{\circ} \mathrm{C}$ to visualize endothelial and smooth muscle cells, respectively.

Event counting and statistical analysis Cell clusters were automatically counted using Gen5 software under cellular analysis tools with threshold intensities set at values less than 10,000 , minimum object size set at $25 \mu \mathrm{m}$ and maximum object size set at $1 \mathrm{~mm}$. These counts along with manual counts of tip cells and stalk cells were taken using still frames at $18,36,60$, and $112 \mathrm{~h}$, respectively, of both control and treated groups. Graphs and statistics were run with GraphPad Prism v.7 Software (La Jolla, CA). $P$ values were calculated via one-way ANOVAs with means and standard deviations plotted per group as compared to vehicle only (control group).

\section{Results}

SVF grown on fibrin, collagen, gelatin, and laminin extracellular matrices behave differently than SVF on Matrigel. Cells form monolayers on the aforementioned ECM, whereas SVF grown on Matrigel undergoes phenotypic change resembling vasculogenesis and angiogenesis after $112 \mathrm{~h}$ (Fig. 1). Subpopulations of SVF cells plated on Matrigel begin to migrate and form clusters ranging in size and cell number after $18 \mathrm{~h}$ of incubation (Fig. 2A, B). These clustering events resemble angioblasts forming blood islands, the initial step s of vasculogenesis in the embryo. The next phenomenon occurs when tip cells subsequently migrate away from the cluster around $36 \mathrm{~h}$ of incubation (Fig. $2 C, D$ ). During angiogenesis, endothelial cells emerge from a pre-existing vessel and remodel surrounding ECM via matrix metalloprotease secretion. Ultimately, these tip cells migrate away from the nascent vessel along with additional endothelial cells creating collateral vessels that will form lumens over time. Tip cells must have additional endothelial cells that migrate behind them to properly signal growth and proliferation events away from the nascent vessel. These specific endothelial cells are termed stalk cells in angiogenesis.
Indeed, after tip cell migration, we see the development of stalk cells growing out of the cluster at $60 \mathrm{~h}$ of incubation as demonstrated in Fig. 2E, F. Stalk cells signal adjacent tip cells through the notch pathway to maintain tip phenotype as well as maintain stalk phenotype. Briefly, VEGF-A signaling through VEGFR-2 causes an upregulation of delta-like ligand 4 which subsequently binds notch to facilitate receptor cleavage by $\gamma$-secretase. Soluble notch can then translocate to the nucleus and cause downstream transcriptional activation; including the upregulation of VEGFR-1, a receptor with low signaling activity via the VEGF-A ligand. VEGFR-2 is downregulated while VEGFR-1 is upregulated on stalk cells, promoting the stalk cell phenotype.

After $60 \mathrm{~h}$ of incubation and up to the endpoint of $112 \mathrm{~h}$, we see the retention of stalk cells as well as tip cell migration and ultimately increased vessel density and complexity including branch points and inosculation events as demonstrated in Fig. $2 G, H$. To validate that the neovasculature was comprised primarily of the endothelial cell population within SVF, cultures incubated to $112 \mathrm{~h}$ were stained with Griffonia simplicifolia 1, an isolectin that binds endothelial cellspecific glycoproteins and is widely used in the field as a rat endothelial cell marker. Figure 3 demonstrates that both on gelatin and Matrigel there is a predominance of endothelial cells; however, only on Matrigel do GS1-positive tip cell and stalk cell phenotypes form.

To determine if SVF was undergoing vasculogenesis and angiogenesis specifically, the assay was repeated in the presence of the inhibitors DAPT, ZM 306416, imatinib mesylate, and ATN-161. DAPT is an inhibitor of the $\gamma$-secretase that cleaves notch receptor to its soluble ligand preventing stalk cell phenotype. ZM 306416 is a small molecule inhibitor of VEGFR-1 (Antczak et al. 2012), again inhibiting stalk cell phenotype via the inhibition of VEGFR-1. Imatinib mesylate blocks platelet-derived growth factor receptor-B (PDGFR-B) (Heymach et al. 2004) which is found on mural cells and instrumental in the recruitment of perivascular support cells to developing endothelial tubes necessary for stabilization. ATN-161 is a small molecule inhibitor of the $\alpha_{5} \beta_{1}$ integrin (Nourse et al. 2009), a membrane-bound protein that binds ECM such as fibrin, fibronectin, and vitronectin (Fig. 4). During the remarkable time points $(18,36,60$, and $112 \mathrm{~h}$ ), the data on cluster number, the cluster size, the percentage of clusters with tip cells, and the percentage of clusters with stalk cells were collected in the presence of each inhibitor and compared to DMSO (vehicle only) control via one-way ANOVA.

Cluster number was significantly reduced in the presence of $25-\mu \mathrm{M}$ DAPT as well as $1-\mu \mathrm{M}$ imatinib mesylate at $36 \mathrm{~h}$ as compared to DMSO controls ( $p<0.05, p<0.005$, respectively, Fig. $5 A$ ). It is possible that the biochemical pathways involved in stalk cell formation as well as mural cell migration may play a role in the recruitment of neighboring SVF cells during initial cell aggregation. In addition, a decreasing trend 

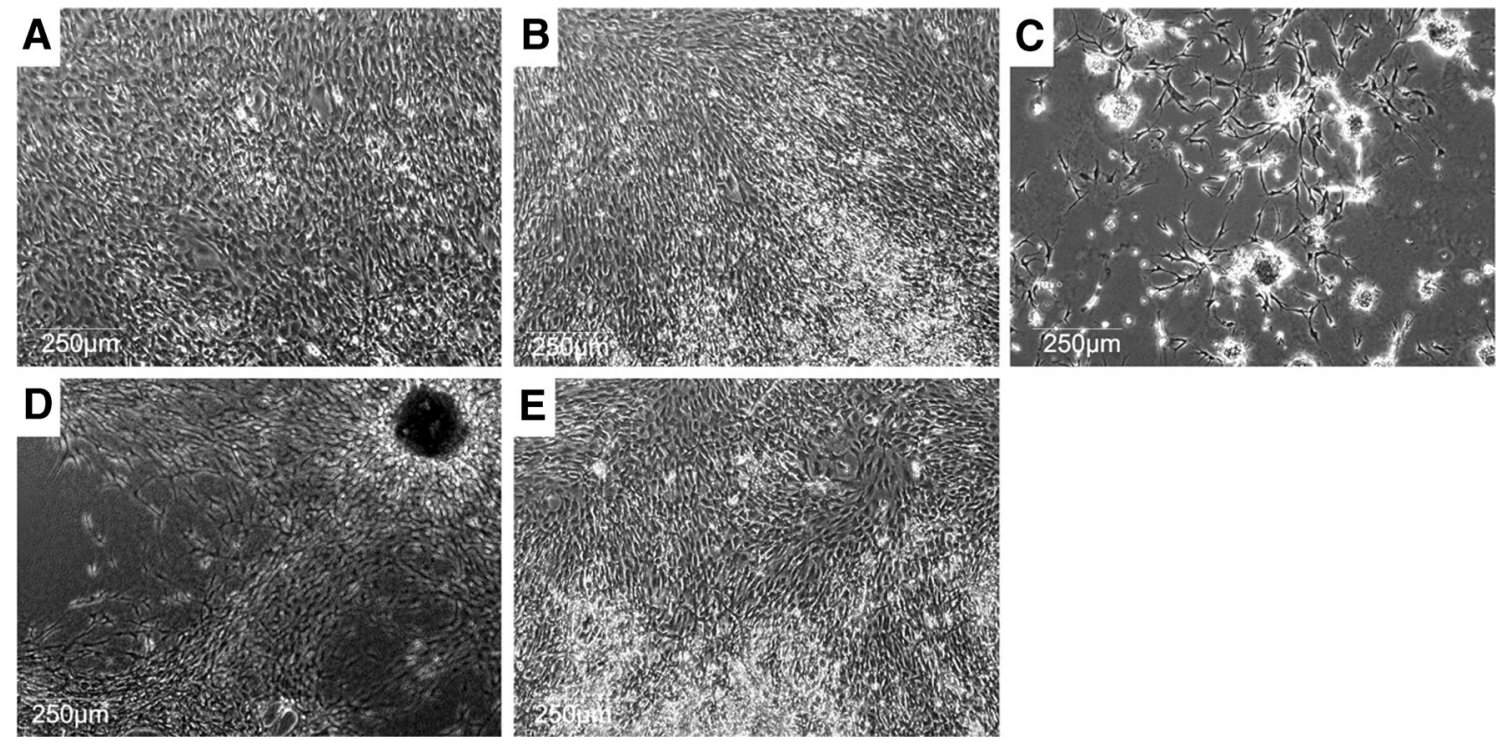

Figure 1. $\times 4$ phase contrast images of SVF grown on $3 \mathrm{mg} / \mathrm{mL}$ collagen I $(A), 1 \%$ gelatin $(B)$, Matrigel $(C), 5 \mathrm{mg} / \mathrm{mL}$ fibrin $(D)$, or $2 \mu \mathrm{g}$ laminin $332(E)$ after $112 \mathrm{~h}$ of incubation. Monolayers of cells are formed on

in overall cluster number over time is noted, which can be explained by the neighboring clusters grouping together forming larger units, decreasing total counts. This phenomenon may be due to a variety of cell-cell signaling promoting cell migration and interaction leading to myofibroblastic contraction pulling groupings together (Supplemental Figure 1). Indeed, myofibroblasts as well as other contractile cells have been found in adipose-derived SVF (Diaz-Flores et al. 2015). Cluster size does not seem to change between inhibitor and non-inhibitor groups; however, there is an increased trend in average size of clusters over $112 \mathrm{~h}$ across all groups (Fig. 5B).

While tip cell phenotype initially begins around $16 \mathrm{~h}$ of incubation, certain clusters retain tip cells even up until $112 \mathrm{~h}$ of incubation. There is a significant reduction in tip cell expression in the presence of imatinib mesylate at $18 \mathrm{~h}$ of incubation $(p<0.05)$ with a non-significant decrease in tip cells in the presence of the other angiogenic inhibitors. Again, at $60 \mathrm{~h}$ of incubation, there is a significant decrease in tip cells in the presence of imatinib mesylate $(p<0.0005)$.

As tip cells migrate, stalk cells form to stabilize and facilitate tip cell migration away from clusters, up until tip cells inosculate with other microvessels, forming a neovascular network. These events occur at $112 \mathrm{~h}$, where control groups begin to decrease tip cell expression because of inosculation events, forming continuous vessel networks. However, cells treated with DAPT have statistically higher amounts of tip cells as compared to DMSO $(p<0.05)$. This retention of tip cells may be attributable to the loss of stalk cell production via notch pathway inhibition. Tip cells still can form and begin initial migration away from clusters, but cannot migrate more than a cell length away due to the lack of stalk cell production. Tip cell percentage at $112 \mathrm{~h}$ in the presence of imatinib mesylate is collagen I $(A)$, gelatin $(B)$ and laminin $332(E)$ with cell clustering demonstrated on Matrigel $(C)$ and fibrin $(D)$. SVF forms microvascular networks on Matrigel $(C)$.

also significantly lower than the vehicle only group $(p<0.05$, Fig. $5 C$ ). These data are corroborated with stalk cell counts at the significant time points. Indeed, while tip cell percentage remains high in the presence of DAPT, and ZM 306416, stalk cell percentages decrease significantly in the presence of $\mathrm{ZM}$ 306416 and imatinib mesylate at $60 \mathrm{~h}$ of incubation (Fig. 5D).

\section{Discussion}

The formation of blood vessels in vivo occurs due to the processes of vasculogenesis during development and angiogenesis during development, pathologic, and physiologic conditions. The study of vasculogenesis and angiogenesis have been aided by in vitro models that have utilized the ability to culture expand endothelial cells and establish conditions that support the development of endothelial tube-like structures in 2D culture (Madri and Williams 1983; Staton et al. 2009; Arnaoutova and Kleinman 2010). However, an in vitro model that recapitulates all vasculogenic and angiogenic processes has not been established.

The formation of tube-like structures by endothelial cells plated onto extracellular matrix has often been described as a model of angiogenesis in vitro but arguably this is not accurate since only one of the processes necessary for angiogenesis occurs - tube formation. The results presented support the conclusion that adipose-derived stromal vascular fraction cell populations plated onto Matrigel, immediately after isolation, exhibit both vasculogenic and angiogenic elements of microvessel formation.

The self-assembly of cells into microvessels requires the appropriate cells to communicate with one another 
Figure 2. $\times 4$ phase contrast images of SVF grown on Matrigel at $18 \mathrm{~h}(A, B) ; 36 \mathrm{~h}(C, D) ; 60 \mathrm{~h}$ $(E, F)$; and $112 \mathrm{~h}(G, H)$. Images $B, D, F$, and $\mathrm{H}$ are $\times 3$ optical zooms of boxed sections of images $A, C, E$, and $G$, respectively. White arrows demonstrate initial cell clustering occurring at $18 \mathrm{~h}$. Tip cell formation occurs at $36 \mathrm{~h}$ as marked by the red arrow. Stalk cell formation and elongation occurs at $60 \mathrm{~h}$ as marked by the blue arrow. Branching (green arrow) and inosculation (yellow arrow) can be seen at $118 \mathrm{~h}$ in vitro.
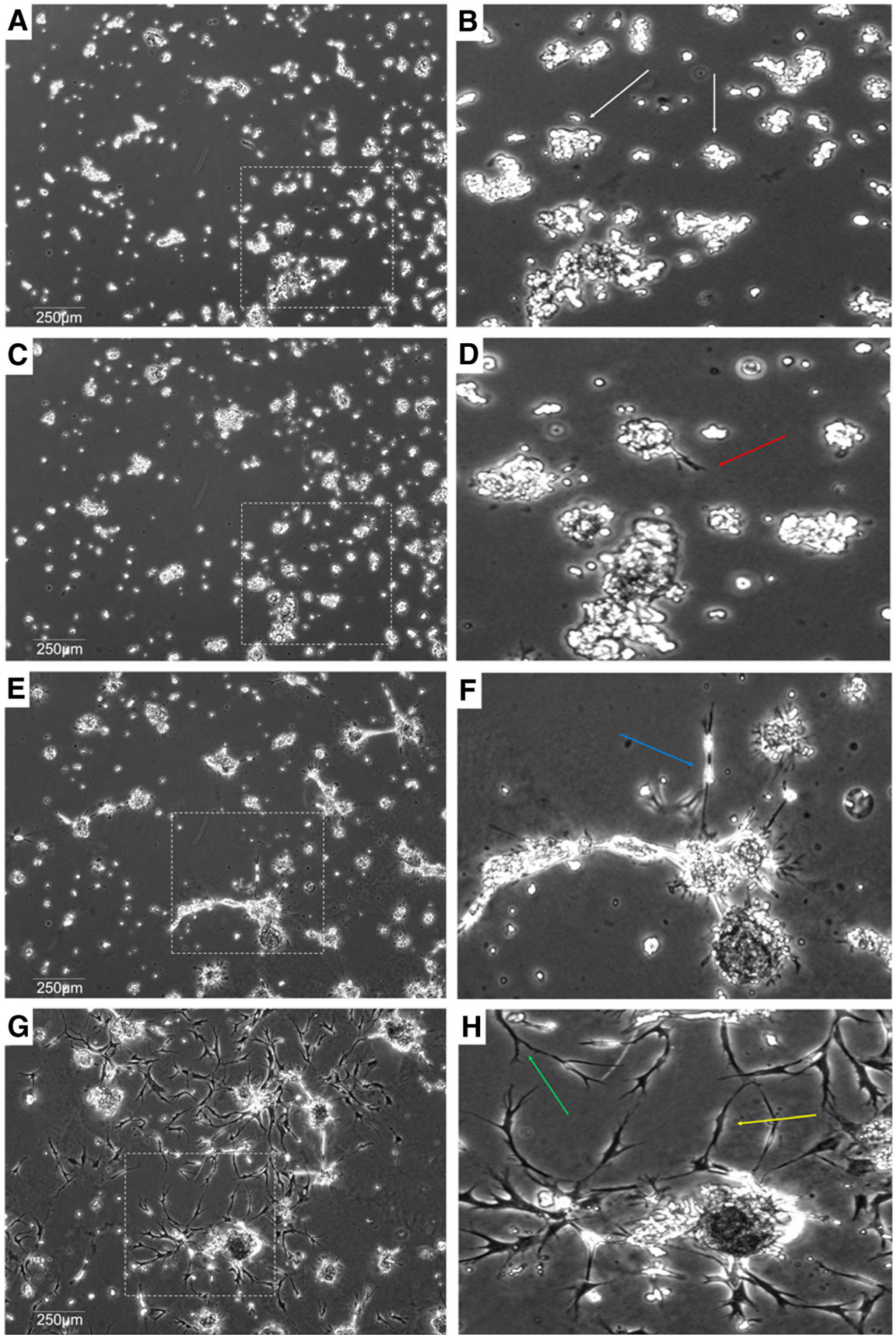

via paracrine and mechanical factors to promote proliferation, migration, and inosculation, ultimately forming functional microcirculation from individualized cellular components (Lin et al. 2016). Recapitulating this process in vitro requires the presence of each cell type that makes up functional microcirculation, including but not limited to endothelial cells, smooth muscle cells, pericytes and tissue resident immune cells (MildmayWhite and Khan 2016). Adipose-derived SVF populations undergo vasculogenesis and angiogenesis as demonstrated by events such as cell clustering, followed by tip cell formation, stalk cell formation, branching, and ultimately complex network formation including the inosculation of adjacent vessel projections. 
Figure 3. $\times 10$ fluorescent images of SVF grown on $1 \%$ gelatin $(A)$ or Matrigel $(B)$ for 112 h. Blue: DAPI, green: Griffonia simplicifolia 1 endothelial specific lectin-FITC, and red: $\alpha$ smooth muscle actinrhodamine.
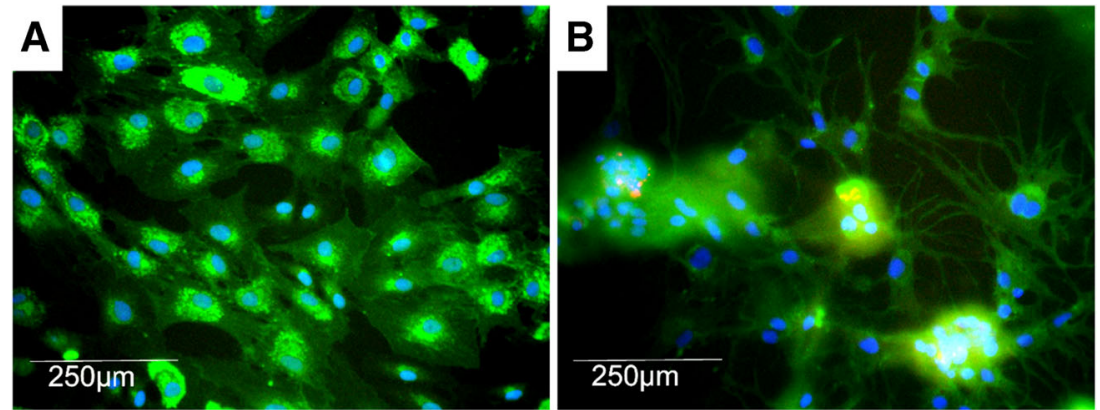

These events can be validated by well-known inhibitors of angiogenesis, some commonly used in the clinic as antiangiogenic tumor pharmacotherapies. In the literature as well as in our assay, DAPT, an inhibitor of the $\gamma$-secretase that cleaves NOTCH to its soluble ligand, prevents endothelial stalk cell formation and subsequent tip cell migration (Tung et al. 2012; Blanco and Gerhardt 2013). While the notch pathway is not endothelial-specific only, it provides an important bottleneck in the promotion of the tip or stalk cell phenotype in endothelial cells. It is highly conserved in many cell types establishing polarity. ZM 306416, a small molecule competitive inhibitor of VEGFR-1 inhibits stalk cell phenotype. Additionally, imatinib mesylate, an inhibitor of PDGFR-B, a receptor found on mural and perivascular support cells, prevents their recruitment to new endothelial tubes via PDGF- $\beta$ ligand chemotaxis. This PDGF axis is instrumental in the mobilization and recruitment of stabilizing cells during angiogenesis, which ultimately leads to retention of non-leaky,

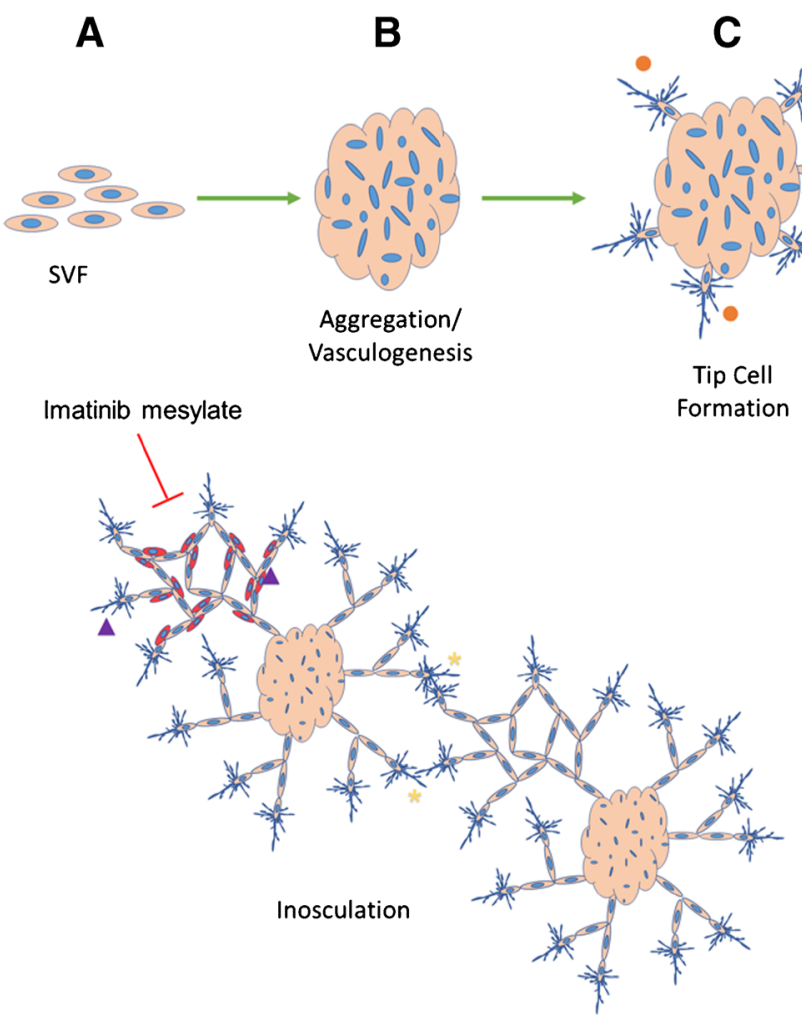

$\mathbf{F}$

Figure 4. Schematic of SVF microvascular assembly on Matrigel in vitro. Digested SVF cells $(A)$ self-assemble into a cluster of cells by $18 \mathrm{~h}(B)$. By $36 \mathrm{~h}$, endothelial cells sprout out of the cluster with dendriticlike extensions (tip cells: orange $\bullet$ ) $(C)$. DAPT, an inhibitor of the $\gamma$ secretase that cleaves notch to its soluble ligand, blocks tip cell signaling to stalk cells, inhibiting stalk cell formation. Stalk cell formation occurs when notch signaling leads to a higher expression of VEGR-1 on the adjacent cell. ZM 306416 blocks VEGFR-1 and thus, stalk cell phenotype. In the absence of inhibitors, stalk cells (black 8 ) migrate away from
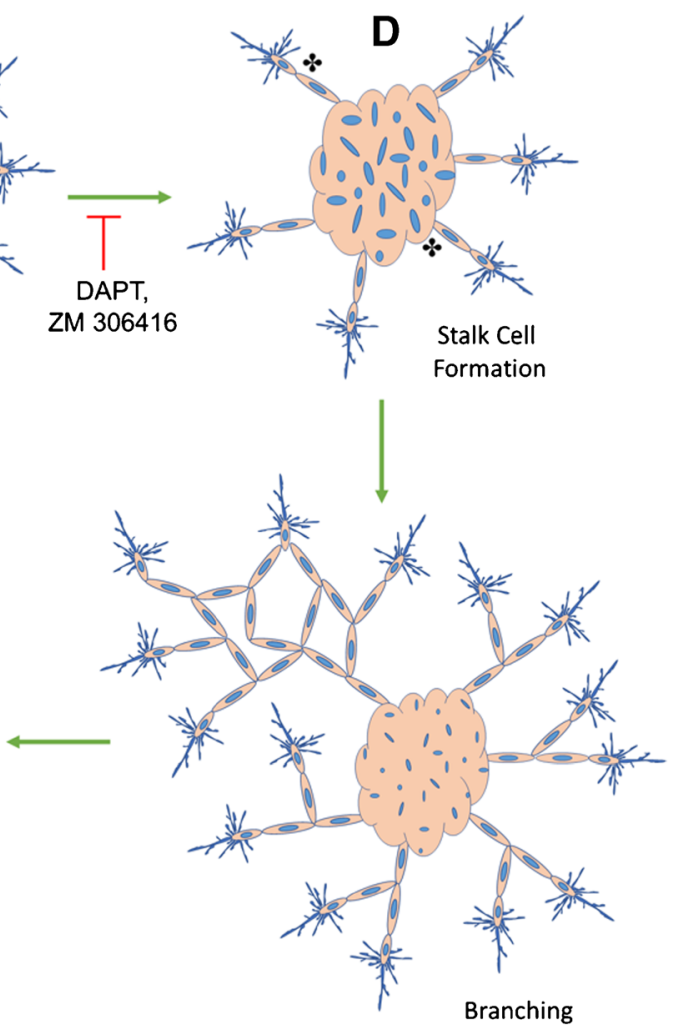

$\mathbf{E}$

clusters behind tip cells by $60 \mathrm{~h}(D)$. Microvascular networks continue to grow after $112 \mathrm{~h}$ and demonstrate increased complexity $(E)$. Networks from adjacent clusters inosculate with one another (yellow $*$ ) and recruit perivascular support cells to endothelial tubes (purple $\mathbf{\Delta})(F)$. PDGFR-B is found on perivascular support cells and activated by endothelial PDGF$\beta$, which signals pericyte recruitment and tube stabilization. Imatinib mesylate inhibits PDGFR-B. 


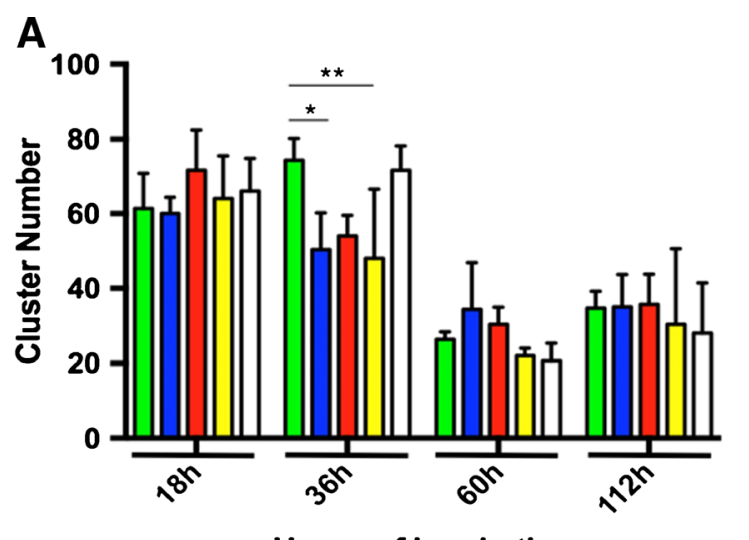

Hours of Incubation

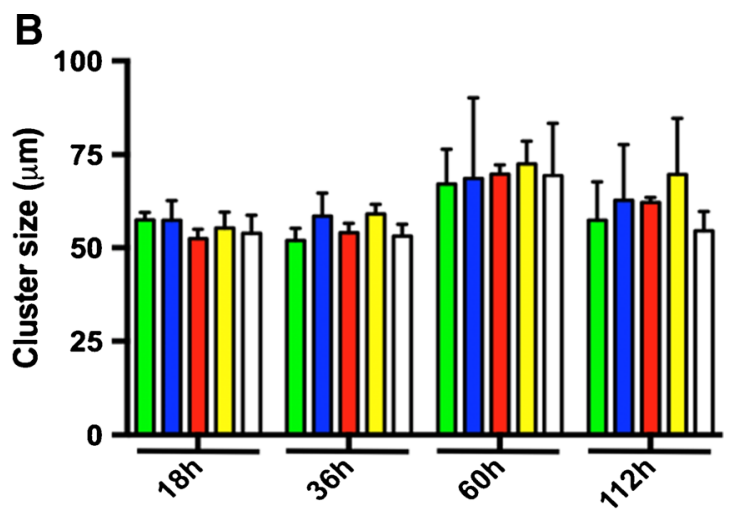

Hours of Incubation

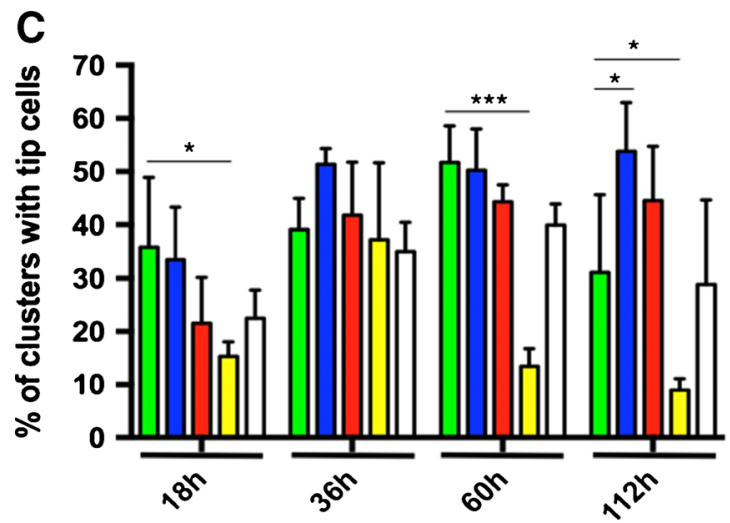

Hours of Incubation

Figure 5. Number of SVF cell clusters (grouping of two or more cells over $25 \mu \mathrm{m}$ in total size) at $18,36,60$, and $112 \mathrm{~h}$ of incubation in the presence of inhibitors $(A)$. Cluster size (micrometer) at $18,36,60$, and $112 \mathrm{~h}$ of incubation in the presence of inhibitors $(B)$. Percentage of clusters containing tip cells at $18,36,60$, and $112 \mathrm{~h}$ of incubation in the

functional neovasculature (Gaengel et al. 2009). These inhibitors validate the vasculogenic and angiogenic processes occurring in this assay and were chosen based from well-known mechanisms of angiogenesis. However, the assay provides the opportunity to validate and test a variety of proangiogenic or antiangiogenic pharmacotherapies as well as test cytokines including but not limited to fibroblast growth factor 2, hepatocyte growth factor, ephrin B1, and others in order to assess additional angiogenic pathways.

Indeed, endothelial cell and mural cell self-assembly and proliferation are required to form functional microvasculature; however, extracellular matrix (ECM) components are necessary to stimulate cell growth and maturation (Moore et al. 2015; Fercana et al. 2017). Fully mature vascular networks restructure surrounding ECM, via matrix metalloproteases, to create a distinct basement membrane composed predominantly

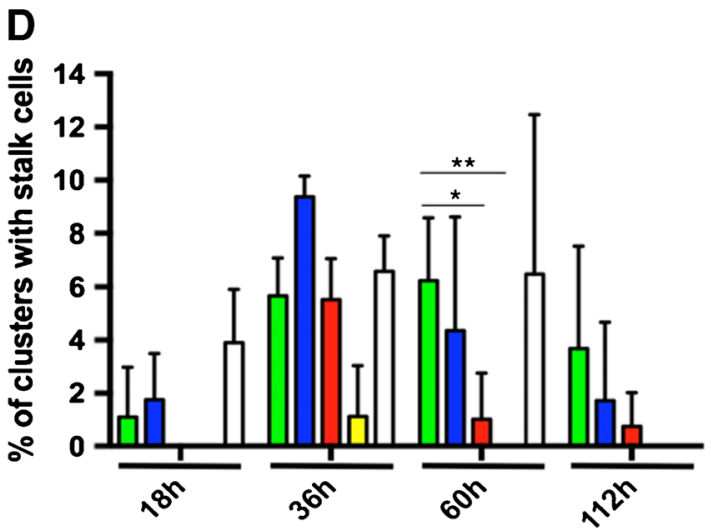

\section{Hours of Incubation}

presence of inhibitors $(C)$. Percentage of clusters containing stalk cells at $18,36,60$, and $112 \mathrm{~h}$ of incubation in the presence of inhibitors $(D)$. Angiogenic inhibitors (in DMSO) were added at days $0,2,4$, and 6 . $p<0.05^{*}, p<0.005 * *, p<0.0005 * * *$.

of type IV collagen and laminins 121 and 332, allowing for appropriate adventitial cell signaling, structural integrity, and decreased permeability (Ebrahem et al. 2010; Sacharidou et al. 2012; Mammoto et al. 2013). Matrigel, a complex mixture of extracellular matrix molecules created from EngelbrethHolm-Swarm mouse tumor, is an ECM derivative that contains basement membrane proteins necessary to stimulate endothelial cells to migrate, proliferate, and create tube-like structure morphologies. As such, many in vitro angiogenesis assays use Matrigel as the dominant ECM prior to cell plating. It is important to note that the initial vasculogenic and angiogenic events occur within the first $24 \mathrm{~h}$ of cell plating on substrates such as Matrigel for pure endothelial cell populations (Hughes 1996). This assay establishes a methodology to evaluate and classify the vasculogenic/angiogenic capability of patient-specific SVF prior to clinical usage. 
Although the current study represents a solely in vitro evaluation of vasculogenic and angiogenic processes by adiposederived SVF cell populations, the discussion of how these results may relate to in vivo vasculogenesis and angiogenesis is warranted. Adipose-derived SVF cell populations are under extensive study for use in clinical applications where tissue revascularization is desired (Carstens et al. 2017). The direct injection of adipose-derived SVF cells into ischemic tissue has been hypothesized to support the formation of new blood vessels in the target tissue. Most studies suggest the action of the SVF is to stimulate new blood vessel formation by angiogenic mechanisms that are by the formation of new vessels from pre-existing vessels. Thus, the SVF cell population is providing a source of paracrine factors. Pre-clinical studies provide an alternative explanation for increased vessel density of SVF-treated ischemic tissue. Using cell markers to evaluate the fate of injected adipose-derived SVF, the cells exhibit the ability to self-assemble into new vessels. The new vessels formed include arterioles, venules, and capillaries, and the cell tracking technology indicates these new vessels originate from the injected SVF cell population (Chang et al. 2012). However, it remains unknown whether the injected SVF exhibits cell aggregation as observed in the current in vitro system. We believe that SVF harbors the appropriate milieu of cells to reform multi-cellular vascular components, including endothelial cells, smooth muscle cells, pericytes, adiposederived stem cells, and additional immune and stromal cells. The development of this SVF-based automated assay of vasculogenesis may permit the assessment of patient-specific SVF cell populations to analyze vasculogenic and angiogenic potential prior to surgical implantation.

Funding information Funding for this study was provided by the Jewish Heritage Fund for Excellence.

Open Access This article is distributed under the terms of the Creative Commons Attribution 4.0 International License (http:// creativecommons.org/licenses/by/4.0/), which permits unrestricted use, distribution, and reproduction in any medium, provided you give appropriate credit to the original author(s) and the source, provide a link to the Creative Commons license, and indicate if changes were made.

\section{References}

Albini A (2016) Extracellular matrix invasion in metastases and angiogenesis: commentary on the Matrigel "Chemoinvasion assay". Cancer Res 76(16):4595-4597

Antczak C et al (2012) A high-content biosensor-based screen identifies cell-permeable activators and inhibitors of EGFR function: implications in drug discovery. J Biomol Screen 17(7):885-899

Arnaoutova I, Kleinman HK (2010) In vitro angiogenesis: endothelial cell tube formation on gelled basement membrane extract. Nat Protoc 5(4):628-635
Blanco R, Gerhardt H (2013) VEGF and notch in tip and stalk cell selection. Cold Spring Harb Perspect Med 3(1):a006569

Bogorad MI et al (2017) Tissue-engineered 3D microvessel and capillary network models for the study of vascular phenomena. Microcirculation

Brown RM et al (2016) Tube-forming assays. Methods Mol Biol 1430: 149-157

Carstens MH et al (2017) Non-reconstructable peripheral vascular disease of the lower extremity in ten patients treated with adipose-derived stromal vascular fraction cells. Stem Cell Res 18:14-21

Chang CC et al (2012) Determinants of microvascular network topologies in implanted neovasculatures. Arterioscler Thromb Vasc Biol 32(1):5-14

Diaz-Flores L et al (2015) Behavior of in situ human native adipose tissue CD34+ stromal/progenitor cells during different stages of repair. Tissue-resident CD34+ stromal cells as a source of myofibroblasts. Anat Rec (Hoboken) 298(5):917-930

Ebrahem Q et al (2010) Cross-talk between vascular endothelial growth factor and matrix metalloproteinases in the induction of neovascularization in vivo. Am J Pathol 176(1):496-503

Fercana GR et al (2017) Perivascular extracellular matrix hydrogels mimic native matrix microarchitecture and promote angiogenesis via basic fibroblast growth factor. Biomaterials 123:142-154

Gaengel K et al (2009) Endothelial-mural cell signaling in vascular development and angiogenesis. Arterioscler Thromb Vasc Biol 29(5): $630-638$

Haug V et al (2015) Comparison between endothelial progenitor cells and human umbilical vein endothelial cells on neovascularization in an adipogenesis mouse model. Microvasc Res 97:159-166

Heymach JV et al (2004) Phase II study of the antiangiogenic agent SU5416 in patients with advanced soft tissue sarcomas. Clin Cancer Res 10(17):5732-5740

Hiscox AM et al (2008) An islet-stabilizing implant constructed using a preformed vasculature. Tissue Eng Part A 14(3):433-440

Hughes SE (1996) Functional characterization of the spontaneously transformed human umbilical vein endothelial cell line ECV304: use in an in vitro model of angiogenesis. Exp Cell Res 225(1):171-185

Jin E et al (2017) Angiogenic characteristics of human stromal vascular fraction in ischemic hindlimb. Int J Cardiol 234:38-47

Kc P et al (2017) Prevascularization of decellularized porcine myocardial slice for cardiac tissue engineering. ACS Appl Mater Interfaces 9(3): 2196-2204

Laschke MW, Menger MD (2015) Adipose tissue-derived microvascular fragments: natural vascularization units for regenerative medicine. Trends Biotechnol 33(8):442-448

Laschke MW, Menger MD (2016) Prevascularization in tissue engineering: current concepts and future directions. Biotechnol Adv 34(2): 112-121

Leblanc AJ, Touroo JS, Hoying JB, Williams SK (2012) Adipose stromal vascular fraction cell construct sustains coronary microvascular function after acute myocardial infarction. Am J Physiol Heart Circ Physiol 302(4):H973-H982

Leblanc AJ, Nguyen QT, Touroo JS, Aird AL, Chang RC, Ng CK, Hoying JB, Williams SK (2013) Adipose-derived cell construct stabilizes heart function and increases microvascular perfusion in an established infarct. Stem Cells Transl Med 2(11):896-905

Lin S et al (2016) Smad signal pathway regulates angiogenesis via endothelial cell in an adipose-derived stromal cell/endothelial cell coculture, 3D gel model. Mol Cell Biochem 412(1-2):281-288

Madri JA, Williams SK (1983) Capillary endothelial cell cultures: phenotypic modulation by matrix components. J Cell Biol 97(1):153165

Maijub JG et al (2015) Concentration-dependent vascularization of adipose stromal vascular fraction cells. Cell Transplant 24(10):2029 2039 
Mammoto T et al (2013) Extracellular matrix structure and tissue stiffness control postnatal lung development through the lipoprotein receptorrelated protein 5/tie2 signaling system. Am J Respir Cell Mol Biol 49(6):1009-1018

Mildmay-White A, Khan W (2016) Cell surface markers on adiposederived stem cells: a systematic review. Curr Stem Cell Res Ther

Moore MC, Pandolfi V, McFetridge PS (2015) Novel human-derived extracellular matrix induces in vitro and in vivo vascularization and inhibits fibrosis. Biomaterials 49:37-46

Morrissette-McAlmon J et al (2017) Adipose-derived perivascular mesenchymal stromal/stem cells promote functional vascular tissue engineering for cardiac regenerative purposes. In: J Tissue Eng Regen Med

Nicosia RF, Ottinetti A (1990) Modulation of microvascular growth and morphogenesis by reconstituted basement membrane gel in threedimensional cultures of rat aorta: a comparative study of angiogenesis in Matrigel, collagen, fibrin, and plasma clot. In Vitro Cell Dev Biol 26(2):119-128

Nourse MB et al (2009) VEGF induces differentiation of functional endothelium from human embryonic stem cells. Implications for tissue engineering. Arterioscler Thromb Vasc Biol

Nunes SS et al (2013) Generation of a functional liver tissue mimic using adipose stromal vascular fraction cell-derived vasculatures. Sci Rep $3: 2141$

Riemenschneider SB et al (2016) Inosculation and perfusion of prevascularized tissue patches containing aligned human microvessels after myocardial infarction. Biomaterials 97:51-61
Sacharidou A, Stratman AN, Davis GE (2012) Molecular mechanisms controlling vascular lumen formation in three-dimensional extracellular matrices. Cells Tissues Organs 195(1-2):122-143

Sasagawa T et al (2016) Endothelial colony-forming cells for preparing prevascular three-dimensional cell-dense tissues using cell-sheet engineering. J Tissue Eng Regen Med 10(9):739-747

Shepherd BR, Hoying JB, Williams SK (2007) Microvascular transplantation after acute myocardial infarction. Tissue Eng 13(12):28712879

Staton CA, Reed MW, Brown NJ (2009) A critical analysis of current in vitro and in vivo angiogenesis assays. Int J Exp Pathol 90(3):195221

Sun X, Altalhi W, Nunes SS (2016) Vascularization strategies of engineered tissues and their application in cardiac regeneration. Adv Drug Deliv Rev 96:183-194

Tung JJ, Tattersall IW, Kitajewski J (2012) Tips, stalks, tubes: notchmediated cell fate determination and mechanisms of tubulogenesis during angiogenesis. Cold Spring Harb Perspect Med 2(2):a006601

Valarmathi MT et al (2017) A novel human tissue-engineered 3-D functional vascularized cardiac muscle construct. Front Cell Dev Biol 5:2

Wagner RC, Matthews MA (1975) The isolation and culture of capillary endothelium from epididymal fat. Microvasc Res 10(3):286-297

Wagner RC, Kreiner P, Barrnett RJ, Bitensky MW (1972) Biochemical characterization and cytochemical localization of a catecholaminesensitive adenylate cyclase in isolated capillary endothelium. Proc Natl Acad Sci U S A 69(11):3175-3179 